\title{
Novel green route towards polyesters-based resin by photopolymerization of star polymers
}

\author{
P. Baheti ${ }^{1,2}$, C. Bonneaud ${ }^{1}$, C. Bouilhac ${ }^{1}$, C. Joly-Duhamel ${ }^{1}$, S. M. Howdle ${ }^{2}$, P. Lacroix-Desmazes ${ }^{1 *}$ \\ ${ }^{1}$ ICGM, ENSCM, CNRS, Univ Montpellier, Montpellier, France \\ ${ }^{2}$ School of Chemistry, University of Nottingham, University Park, Nottingham NG7 2RD, United Kingdom
}

Received 20 April 2019; accepted in revised form 8 July 2019

\begin{abstract}
Bio-based star-shaped poly( $\varepsilon$-caprolactone)s (S-PCL) derived from sugar-based $D$-sorbitol as an initiator were obtained via solvent-free enzymatic ring-opening polymerization (eROP). The star S-PCL were converted into UV-curable maleates by employing maleic anhydride for subsequent crosslinking with tri(ethylene glycol) divinyl ether (DVE-3) in the presence of Darocur 1173 as a radical photoinitiator. The kinetics of the UV-induced radical copolymerization was monitored by real-time Fourier-Transform InfraRed (FTIR) spectroscopy, which revealed that the star S-PCL maleate/divinyl ether system was not scavenged by molecular oxygen (donor/acceptor polymerization). The UV-crosslinking reaction was fast $(\sim 10 \mathrm{~s})$ to reach near quantitative conversions. The S-PCL maleate / divinyl ether liquid formulation cast on glass substrates successfully gave films upon UV-crosslinking. The thermal properties of the polymer films and their precursor polymers were characterized by differential scanning calorimetry (DSC) and thermogravimetric analysis (TGA). Finally, the crosslinked polymer film demonstrated promising adhesive properties on steel, aluminum and glass substrates.
\end{abstract}

Keywords: coatings, star polymers, bio-based polymers, enzymatic polymerization, UV-crosslinking

\section{Introduction}

Hyperbranched star-like polymers are increasingly gaining attention for coatings due to lower melt viscosity, higher solubility in many solvents and to their compact structure that minimizes chain entanglements, while in the same time, the large number of functional end-groups enables efficient crosslinking compared to suitable linear analogues [1-3]. Poly $(\varepsilon-$ caprolactone) (PCL) is one of the most valuable biodegradable and biocompatible polyester. The hyperbranched star-like PCL resins tend towards lower melt viscosity, which decreases the solvent content of coating and in turn reduces or eliminates the volatile organic compounds (VOC)s emission suitable for the film formation for powder coating $[4,5]$.

Typically, star-like PCL are synthesized from polyhydric alcohols (such as pentaerythritol [6-9], di-trimethylolpropane [10], $D$-sorbitol [11], dipentaerythritol [10] etc.) as initiators that constitute the core of the star. The most widely investigated hyperbranched cores in the field of coatings are the two commercially available Boltorn ${ }^{\mathrm{TM}}$ (hyperbranched aliphatic polyesters) $[2,12,13]$ and Hybrane ${ }^{\mathrm{TM}}$ (hyperbranched polyester amides) [3]. However, sorbitol is of particular interest as the core of the star polyester then comes from renewable sources such as corn-starch, cellulose, cassava, wheat, etc. Furthermore, considering its multifunctional nature, sorbitol enables to create functional polymers suitable for preparation of resins for coatings or adhesives due to their low viscosity [14-17].

Indeed, it is well established that the gradual deprivation and rising cost of fossil reserves and environmental impact of fossil- $\mathrm{CO}_{2}$ are driving the current 
market trend towards renewable plant-based alternatives which also benefit from building-blocks of diverse functionality for the creation of sustainable materials $[18,19]$. An alternative to this petroleumbased feedstock is lignocellulose biorefinery which is the most abundant, bio-renewable, carbon-neutral and non-edible biomass currently available [20,21]. Lignocellulosic biomass is increasingly gaining attention to produce lignin derivable sugars and monomeric chemicals $[17,22]$. For example, commercially valuable and the least expensive sugars are sorbitol and 5-(hydroxymethyl)furfural (5-HMF). Both are among the top 16 building blocks obtained from lignin from which numerous chemicals and polymeric materials can be derived [17]. For instance, although PCL is mainly derived from commercial nonrenewable $\varepsilon$-caprolactone ( $\varepsilon$-CL), a two-step pathway starting from 5-HMF platform can yield bio-sourced $\varepsilon$-CL and potentially opens opportunities to create bio-based PCL [17].

Furthermore, Novozym 435 (an immobilized Candida antarctica lipase $\mathrm{B}, \mathrm{CaLB}$ ) is the benchmark enzyme that is extensively investigated as a catalyst for polycondensation and for enzymatic ring opening polymerization (eROP) reactions in the bulk and in organic media [23-25]. Novozym 435 is known to exhibit partial regioselectivity towards primary alcohols. Benefiting from this effect, in our previous work, we proposed a fully green route using Novozym 435 as a catalyst in solvent-free bulk condition to yield novel star polymers of three PCL arms with pendant hydroxyl groups from a sorbitol core [26]. Considering the synthetic approach for the sorbitolbased PCL (i.e. enzymatic ROP and the fact that no trace of metal contamination is present in the polyester polyols), such star-like PCL materials with terminal hydroxyl groups are suitable to bring adhesive properties convenient for external resin for infrastructure (e.g. pipelines, bridges, buildings, etc.) [27].
Photo-curable coatings are considered to be much more eco-friendly and energy-saving than thermally cured coatings. In addition, a UV-crosslinked network can be obtained within tens of seconds or even faster without solvent thus reducing VOC emissions [4, 28-30]. These multifunctional hyperbranched starlike polymers are functionalized to make them responsive to photochemical initiated curing, generally by end-capping with acrylates or, less commonly, methacrylates $[2,12]$. From the industrial point-ofview, the fast kinetics of acrylates makes them highly desirable, but the drawback is the sensitivity of their radical polymerization to molecular $\mathrm{O}_{2}$ inhibition resulting in an incomplete cure or longer curing time. This can result in poor quality tacky upper surfaces or, in the worst case, a complete failure to cure [31]. Since open-air curing is the easiest method for industrial processing, $\mathrm{O}_{2}$ inhibition is a rather common issue and is essentially universal to free radical photocuring applications [31].

An alternative is to use maleate as an electron acceptor monomer (A) for UV-curing in combination with electron donor (D) monomers, such as a divinyl ether [3]. This kind of A-D copolymerization is fast and less sensitive to $\mathrm{O}_{2}$ than acrylate polymerization [32]. In addition, it is known that vinyl ether double bonds do not homopolymerize in the presence of free radicals which is the case with acrylates [33]. The radical photoinitiator (PI), for example, Darocur 1173 produces reactive benzoyl radical $\left(R^{*}\right)$ by homolytic scission in the initiation step and in the propagation step the vinyl ether/maleate systems follow an electron donor-acceptor free radical mechanism to give alternating copolymer [33]. The design of a branched/star macromolecule is actually ideal for film forming applications. Indeed, as emphasized earlier the viscosity is lower, but the large number of functional end-groups enables efficient crosslinking [3].

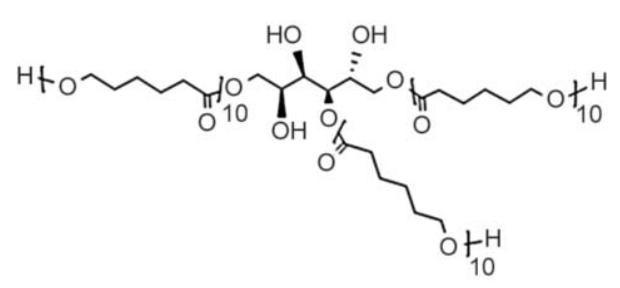

Star D-sorbitol[(PCL) $\left.{ }_{30} \mathrm{OH}_{3}\right] \mathrm{OH}_{3}$

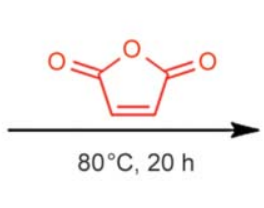

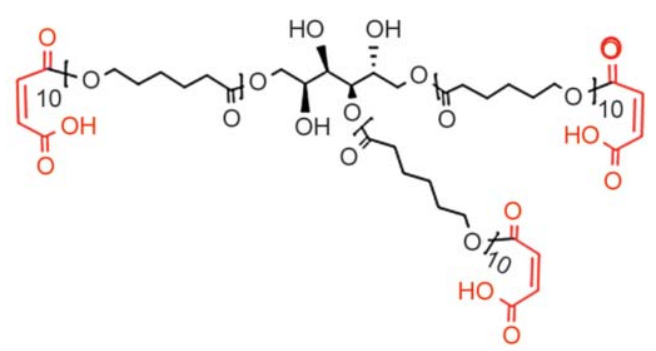

Star D-sorbitol[(PCL) $\left.)_{30} \mathrm{MA}-\mathrm{COOH}_{3}\right] \mathrm{OH}_{3}$

Figure 1. End-functionalization of bio-based star $D$-sorbitol-PCL $\left(3100 \mathrm{~g} \cdot \mathrm{mol}^{-1}\right)$ with maleic anhydride. 


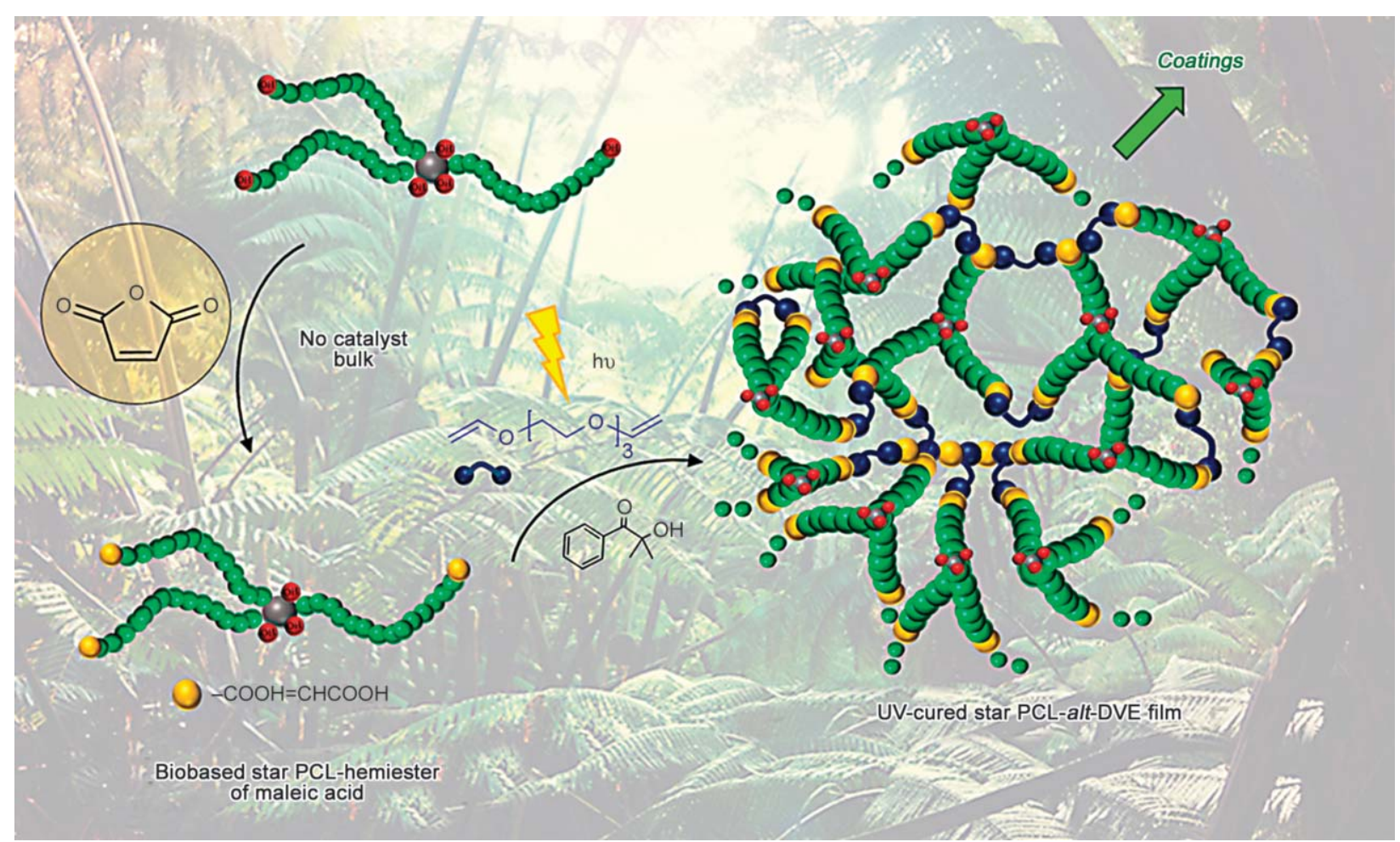

Figure 2. Star $D$-sorbitol-PCL functionalization with maleic anhydride and synthesis of UV-cured films via UV-induced DVE polymerization reaction in the presence of Darocur 1173 as a photoinitiator.

In this work, a three-arm star-PCL was synthesized by eROP of $\varepsilon$-CL from $D$-sorbitol as an initiator using Novozym 435 catalyst and functionalized with maleic anhydride (Figure 1) to give a star PCL-hemiester of maleic acid that possesses a UV polymerizable maleate group.

The UV-cured films of star PCL maleate were prepared using tri(ethylene glycol) divinyl ether in the presence of Darocur 1173 as a photoinitiator (Figure 2). The photopolymerization kinetics were monitored by using real-time Fourier-Transform InfraRed (FTIR) spectroscopy. The PCL networks were characterized by DSC and TGA. The gel content of the resin and adhesion on glass and metallic substrates were then investigated.

\section{Experimental}

\subsection{Materials}

$\varepsilon$-Caprolactone ( $\varepsilon$-CL, 97\%), D-sorbitol ( $>98 \%)$, maleic anhydride (MAH, 99\%), 2-hydroxy-2-methyl propiophenone (Darocur 1173, 100\%), tri(ethylene glycol) divinyl ether (DVE-3, 98\%) and 2-chloro4,4,5,5-tetramethyl-1,3,2-dioxaphospholane (ClTMDP, 95\%) were purchased from Sigma (France). $\varepsilon$-CL was dried over $\mathrm{CaH}_{2}$ for $48 \mathrm{~h}$ followed by vacuum distillation and stored under an inert atmosphere. $D$-sorbitol was stored in a desiccator and dried under vacuum at $25^{\circ} \mathrm{C}$ overnight before use. Novozym 435 (10 wt $\%$ of Candida antarctica (CaLB) immobilized on crosslinked acrylic resin; enzyme activity is 5000 units per mg of protein) was kindly donated by Novozymes (Denmark), stored at $4{ }^{\circ} \mathrm{C}$, dried overnight under vacuum $\left(25^{\circ} \mathrm{C}\right)$ and degassed for $30 \mathrm{~min}$ before use. All the solvents were of analytical grade or HPLC-grade and used as received. Polypropylene films (thickness: $6 \mu \mathrm{m}$ ) were purchased from Goodfellow (Huntingdon, England) and used as received.

\subsection{Methods}

\subsubsection{Solvent-free synthesis of star polycaprolactone from $D$-sorbitol using Novozym 435 as the catalyst}

The synthesis protocol for $M_{\mathrm{n}}^{\mathrm{targ}}=3200 \mathrm{~g} \cdot \mathrm{mol}^{-1}$ was adapted from Baheti et al. [26]. The glassware was flame dried before use. $\varepsilon$-CL $(5.15 \mathrm{~g}, 45.12 \mathrm{mmol})$ was added into a three neck round bottom flask equipped with a mechanical stirrer, under inert conditions (argon) and heated in an oil-bath at $110^{\circ} \mathrm{C}$. $D$-Sorbitol (293 mg, $1.61 \mathrm{mmol})$ was then introduced under mechanical agitation at $300 \mathrm{rpm}$. Although the reaction mixture was initially biphasic, a homogeneous melt of $D$-sorbitol and $\varepsilon$-CL was observed within $30 \mathrm{~min}$. Subsequently, the temperature was reduced to $90^{\circ} \mathrm{C}$ and Novozym 435 beads 
(515 mg, $10 \mathrm{wt} \%$ with respect to $\varepsilon-\mathrm{CL}$ ) were introduced. The reaction was continued for $3 \mathrm{~h}(10 \mathrm{wt} \%$ Novozym 435, 93\% conversion). After polymerization, the reaction mixture was dissolved in THF and the enzyme beads were separated by filtration. Subsequently, the excess of solvent was evaporated, and the crude polymer was purified by precipitation into cold ethanol from THF and dried under vacuum. The gravimetric yield after recycling enzyme was $63 \%$. SEC-MALS $($ THF $): M_{\mathrm{n}}$ SEC-MALS $=3100 \mathrm{~g} \cdot \mathrm{mol}^{-1}$, $Ð=1.39 ; M_{\mathrm{n}}{ }^{31} \mathrm{P}-\mathrm{NMR}=3200 \mathrm{~g} \cdot \mathrm{mol}^{-1}$ and $N_{\text {arms }}\left({ }^{31} \mathrm{P}-\right.$ NMR) 3, where ${ }^{31} \mathrm{P}-\mathrm{NMR}$ was used after phosphitylation reaction, as detailed in a previous publication, to quantify the number of arms [26].

\subsubsection{Functionalization of star $D$-sorbitol- $\mathrm{PCL}_{\mathrm{n}} \mathrm{OH}_{\mathrm{x}}$ with maleic anhydride to obtain star $D$-sorbitol[PCL $\left.\mathbf{P}_{\mathbf{n}}-\mathbf{M A}_{\mathbf{x}}\right]$}

The protocol for end-functionalization of star $D$-sorbitol- $\mathrm{PCL}_{\mathrm{n}} \mathrm{OH}_{\mathrm{x}}$ polymers (star polymers synthesized by using Novozym 435 as a catalyst) was adapted from the procedure by Lacroix-Desmazes et al. [34]. A general procedure for the synthesis of star $D$-sor-

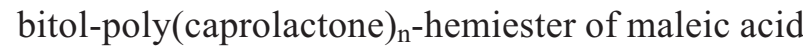
$\left(D\right.$-sorbitol $\left.\left[\mathrm{PCL}_{\mathrm{n}}-\mathrm{MA}_{\mathrm{x}}\right]\right)$ is as followed. Purified star $D$-sorbitol- $\mathrm{PCL}_{\mathrm{n}} \mathrm{OH}_{\mathrm{x}}(2.01 \mathrm{~g}, 0.65 \mathrm{mmol})$ $\left(M_{\mathrm{n}}{ }^{1} \mathrm{H}-\mathrm{NMR}(\operatorname{arm})=1170 \mathrm{~g} \cdot \mathrm{mol}^{-1} ; M_{\mathrm{n}}{ }^{\text {SEC-MALS }}=\right.$ $3100 \mathrm{~g} \cdot \mathrm{mol}^{-1}$ so $M_{\mathrm{n}}{ }^{\text {SEC-MALS }}(\mathrm{star}) / M_{\mathrm{n}}{ }^{1} \mathrm{H}-\mathrm{NMR}(\mathrm{arm}) \sim 3$ and $\oslash=1.39)$ and MAH $\left(1.27 \mathrm{~g}, 98.06 \mathrm{~g} \cdot \mathrm{mol}^{-1}\right.$, $13 \mathrm{mmol}$ ) were added to a round bottom flask (RBF) at 1:20 molar ratio (i.e. 3.3 excess vs. the six hydroxyl groups of the star polymer). The mixture was placed under argon for $30 \mathrm{~min}$ before immersing the RBF to a preheated oil bath set at $80^{\circ} \mathrm{C}$. The mixture was reacted at $80^{\circ} \mathrm{C}$ under this inert atmosphere, typically for $2 \mathrm{~h}$, until $99.9 \%$ end-functionalization was monitored by ${ }^{1} \mathrm{H}-\mathrm{NMR}$. The star $D$-sorbitol[ $\left.\mathrm{PCL}_{\mathrm{n}}-\mathrm{MA}_{\mathrm{x}}\right]$ was purified by adding an excess of cold diethyl ether where the precipitates were allowed to settle at $4{ }^{\circ} \mathrm{C}$ overnight. The excess of supernatant (with MAH) was decanted and this operation was repeated threetime (purity was assessed by ${ }^{1} \mathrm{H}-\mathrm{NMR}$ ). The precipitates were vacuum dried at $25^{\circ} \mathrm{C}$ overnight. The yield of the recovered product was $\sim 56 \%(1.24 \mathrm{~g})$.

${ }^{1} \mathrm{H}-\mathrm{NMR}\left(400 \mathrm{MHz}, \mathrm{DMSO}-d_{6}, \mathrm{ppm}\right) \delta: 6.38(\mathrm{~d}$, $\left.{ }^{3} J_{\mathrm{H}-\mathrm{H}}=12.0 \mathrm{~Hz},=\mathrm{CH}\right), 6.34\left(\mathrm{~d},{ }^{3} J_{\mathrm{H}-\mathrm{H}}=12.0 \mathrm{~Hz}\right.$, $=\mathrm{CH}), 4.08\left(\mathrm{t},-\mathrm{CH} \mathrm{H}_{2}-\mathrm{OC}(\mathrm{O}) \mathrm{CH}=\mathrm{CH}-\mathrm{COOH}\right), 4.00$ $\left(\mathrm{t}\right.$, methylene ester $\left.-\mathrm{CH}_{2} \mathrm{OC}(\mathrm{O})-\right), 2.28(\mathrm{t}$, methylene in $\alpha$ position to carbonyl group $-\mathrm{CH}_{2}-\mathrm{C}(\mathrm{O})-$ ), 1.55 (m, $-\mathrm{C}(\mathrm{O}) \mathrm{CH}_{2} \mathrm{CH}_{2} \mathrm{CH}_{2} \mathrm{CH}_{2} \mathrm{CH}_{2} \mathrm{O}-$ ), 1.31 (m,
$\left.-\mathrm{C}(\mathrm{O}) \mathrm{CH}_{2} \mathrm{CH}_{2} \mathrm{CH}_{2} \mathrm{CH}_{2} \mathrm{CH}_{2} \mathrm{O}-\right)$. Isomerization of the double bond into the fumaric derivative (typical ${ }^{3} J_{\mathrm{H}-\mathrm{H}}$ values $\left.=15.6-16 \mathrm{~Hz}\right)$ was not observed.

\subsubsection{Photo-curable formulation of star $D$-sorbitol[PCL $\left.\mathbf{L}_{\mathrm{n}}-\mathbf{M A}_{\mathbf{x}}\right]$}

The trifunctional star $D$-sorbitol[(PCL) 30 -MA$\left.\mathrm{COOH}_{3}\right] \mathrm{OH}_{3}\left(103 \mathrm{mg}, 33 \mu\right.$ moles, $M_{\mathrm{n}}$ SEC-MALS $=$ $3100 \mathrm{~g} \cdot \mathrm{mol}^{-1}$ ) as an electron acceptor (A) was mixed with bifunctional tri(ethylene glycol) divinyl ether $\left(\mathrm{H}_{2} \mathrm{C}=\mathrm{CH}\left(\mathrm{OCH}_{2} \mathrm{CH}_{2}\right)_{3} \mathrm{OCH}=\mathrm{CH}_{2}, \quad 10.3 \mathrm{mg}\right.$, $202.25 \mathrm{~g} \cdot \mathrm{mol}^{-1}, 50.9 \mu$ moles, DVE-3) as an electron donor (D) in a 2:3 A/D molar ratio; that is to say a stoichiometric ratio between hemiester of maleic acid on star PCL and vinyl ether functions of DVE-3. Darocur 1173 (4.5 mg, $4 \mathrm{wt} \%$ respect to the total weight of the blend) as a photoinitiator along with a minimal amount of acetone $(\sim 150 \mu 1,117.6 \mathrm{mg})$ was added to the mixture followed by intensive mixing (vortexing $\sim 3-5 \mathrm{~min}$ ) at ambient condition up to the formation of a clear, homogeneous viscous liquid.

\subsubsection{Real-time Fourier Transform-InfraRed spectroscopy}

Real time-FTIR was employed for measuring the photopolymerization kinetics on a Thermo Scientific Nicolet 6700 FTIR (Waltham, USA) and were analyzed using an OMNIC 32 software. The crosslinking reaction proceeded under UV irradiation (OmniCure S2000 Spot UV curing system, $200 \mathrm{~W}, 250-450 \mathrm{~nm}$, Mercury lamp) calibrated with OmniCure R2000 UV Radiometer. The real intensity imparted to the samples was $10 \mathrm{~mW} \cdot \mathrm{cm}^{-2}$ measured using radiometer (Solatell). One drop of the above mixture was deposited on the Attenuated Total Reflectance (ATR) unit of the infrared spectrometer where it was exposed to UV irradiation for $300 \mathrm{~s}$ for crosslinking. The kinetics was monitored by real-time FTIR, following the disappearance of the bands at 1615 and $1635 \mathrm{~cm}^{-1}$ corresponding to the vinyl ether.

Kinetics of photopolymerization was performed in the absence of air, by placing a polypropylene film (PP) above the formulation, to prevent atmospheric oxygen from diffusing into the sample.

\subsubsection{Films of star $D$-sorbitol $\left[P C L_{n}-\right.$ alt-MA $\left.A_{x}\right]$ resin and $\mathrm{UV}$-curing procedure}

The above stoichiometric solution was cast onto glass slides at a thickness of about $25 \mu \mathrm{m}$ using a film applicator bar coater (Sheen 1117/100 mm, UK). The 
glass slides were immediately placed on the conveyor under a UV production-curing unit (Fusion UV, LC6B Benchtop Conveyor) equipped with a UV vapor mercury lamp (type H, Fusion F300S, $120 \mathrm{~W} \cdot \mathrm{cm}^{-1}, 200-600 \mathrm{~nm}$ ) (Hampshire, England). Finally, the glass slides were passed repeatedly under the UV lamp at a speed of $1 \mathrm{~m} \cdot \mathrm{min}^{-1}$.

\subsubsection{Differential scanning calorimetry}

DSC analyses were performed on a Q2000 TA instrument (Netzsch, Selb, Germany) calibrated with an indium standard under $\mathrm{N}_{2}$ flow. In a standard experiment, the sample $(2-5 \mathrm{mg})$ was placed in an aluminum pan with a blank reference pan in the instrument. DSC measurements were performed in a temperature range from -80 to $100^{\circ} \mathrm{C}$ at a heating/cooling rate of $10^{\circ} \mathrm{C} \cdot \mathrm{min}^{-1}$. The crystallization temperature $\left(T_{\mathrm{c}}\right)$ and the melting temperature $\left(T_{\mathrm{m}}\right)$ were taken from the second cycle.

\subsubsection{Thermogravimetric analysis}

Thermogravimetric analyses of the UV-cured coatings were performed on TG209 F1 (Netzsch, Selb, Germany). The samples were heated from 25 to $600^{\circ} \mathrm{C}$ at a heating rate of $10^{\circ} \mathrm{C} \cdot \mathrm{min}^{-1}$ in the air (Air Liquide) at a constant purge rate of $40 \mathrm{ml} \cdot \mathrm{min}^{-1}$ in an alumina pan.

\subsubsection{Gel content}

The gel content of the star $D$-sorbitol $\left[\mathrm{PCL}_{\mathrm{n}}\right.$-alt$\mathrm{MA}_{\mathrm{x}}$ ] coatings was evaluated as per ASTM D 276501 . The gel content (insoluble fraction) of star $D$-sorbitol[ $\mathrm{PCL}_{\mathrm{n}}$-alt $\left.-\mathrm{MA}_{\mathrm{x}}\right]$ coatings was determined by extraction with acetone. S-PCL3100 coating films were weighed and then immersed in the extracting solvent (acetone) for $24 \mathrm{~h}$. After the extraction, the remaining coating films were removed, dried at $45^{\circ} \mathrm{C}$ under vacuum $\left(10^{-2} \mathrm{mbar}\right)$ for $24 \mathrm{~h}$, and reweighed. The gel content was determined using Equation (1):

Gel content $=\frac{w_{1}}{w_{0}} \cdot 100$

where $w_{0}$ is the initial weight of the sample $[\mathrm{g}]$ and $w_{1}$ is the weight of the sample after extraction $[\mathrm{g}]$.

\subsubsection{Adhesion strength}

Adhesion properties of the coated films were characterized using the ASTM D3359 standard test method by using a TQC CC2000 cross-cut adhesion test (TQC Sheen, Netherlands). A pattern of 25 squares was obtained with a cross-hatch cutter on the film. A standard tape was then applied and pulled-off. The area was then inspected and rated according to the percentage of the surface of the cross-cut area from which flaking has occurred. Six levels of adhesion exist from 0 which an area affected more than $65 \%$ of the lattice and 5 for completely smooth edges of the cuts.

\section{Results and discussion}

The enzymatic ROP of $\varepsilon$-CL from the $D$-sorbitol core to create a star $D$-sorbitol[ $\left.(\mathrm{PCL})_{\mathrm{n}} \mathrm{OH}_{\mathrm{x}}\right]$ possessing terminal hydroxyl groups was discussed in a previous paper from our group [26]. Star $D$-sorbitol $\left[(\mathrm{PCL})_{30} \mathrm{OH}_{3}\right] \mathrm{OH}_{3}$ with $M_{\mathrm{n}}$ SEC-MALS $\sim 3100 \mathrm{~g} \cdot \mathrm{mol}^{-1}$ was investigated to determine the efficiency of endfunctionalization with maleic anhydride (MAH) (Figure 1). As a reminder, the star $D$-sorbitol $\left[(\mathrm{PCL})_{30} \mathrm{OH}_{3}\right] \mathrm{OH}_{3}(\mathrm{~S}-\mathrm{PCL} 3100)$ has an average of 3 PCL arms, 3 pendant hydroxyl groups on the $D$-sorbitol core and has $M_{\mathrm{n}}^{\text {SEC-MALS }}=3100 \mathrm{~g} \cdot \mathrm{mol}^{-1}, D=$ 1.39 and $M_{\mathrm{n}}{ }^{31} \mathrm{P}-\mathrm{NMR}=3200 \mathrm{~g} \cdot \mathrm{mol}^{-1}$. A detailed analysis by ${ }^{1} \mathrm{H}$ and ${ }^{31} \mathrm{P}-\mathrm{NMR}, \mathrm{SEC}$ and MALDI-TOF revealed that linear PCL and cyclic PCL were minor impurities of the star $D$-sorbitol-PCL.

\subsection{Functionalization of star $D$-sorbitol- $\mathrm{PCL}_{n} \mathrm{OH}_{x}$ with maleic anhydride}

The derivatization of the hydroxyl groups (either at the chain-ends of PCL arms or on the sorbitol core) into hemiester of maleic acid proceeded in the bulk in the absence of catalyst and at moderate temperature $\left(80^{\circ} \mathrm{C}\right)$. A quantitative conversion was reached within $2 \mathrm{~h}$. The functionalization was monitored using ${ }^{1} \mathrm{H}-\mathrm{NMR}$ by measuring the decrease of methylene end-group resonances $\mathbf{y}$ compared to the methylene $\mathbf{c}$ in the PCL backbone (Figure 3a). The preand post-functionalized S-PCL3100 are represented in ${ }^{1} \mathrm{H}-\mathrm{NMR}$ spectra (Figure 3).

The degree of substitution in the functionalization was nearly $100 \%$ as the hydroxymethylene proton resonance $\mathbf{y}$ at $\delta 3.63 \mathrm{ppm}$ (Figure 3a) completely disappeared at the end of the post-functionalization reaction (Figure $3 b$ ). In addition, there was no trace of residual MAH at $\delta 7.46 \mathrm{ppm}(-\mathrm{CH}=\mathrm{C} H-\mathrm{C}(\mathrm{O}) \mathrm{O}-)$ after purification (Figure $3 \mathrm{~b}$ ). It was further observed that new peaks appeared at $\delta 4.08$ ppm corresponding to the methylene protons $\mathbf{b}$ in $\alpha$-position of the maleate group $\left(-\mathrm{CH}_{2}-\mathrm{O}-(\mathrm{C}=\mathrm{O})-\mathrm{CH}=\mathrm{CH}-\right)$ and at $\delta$ $6.34 \mathrm{ppm}$ corresponding to the methine groups of the 


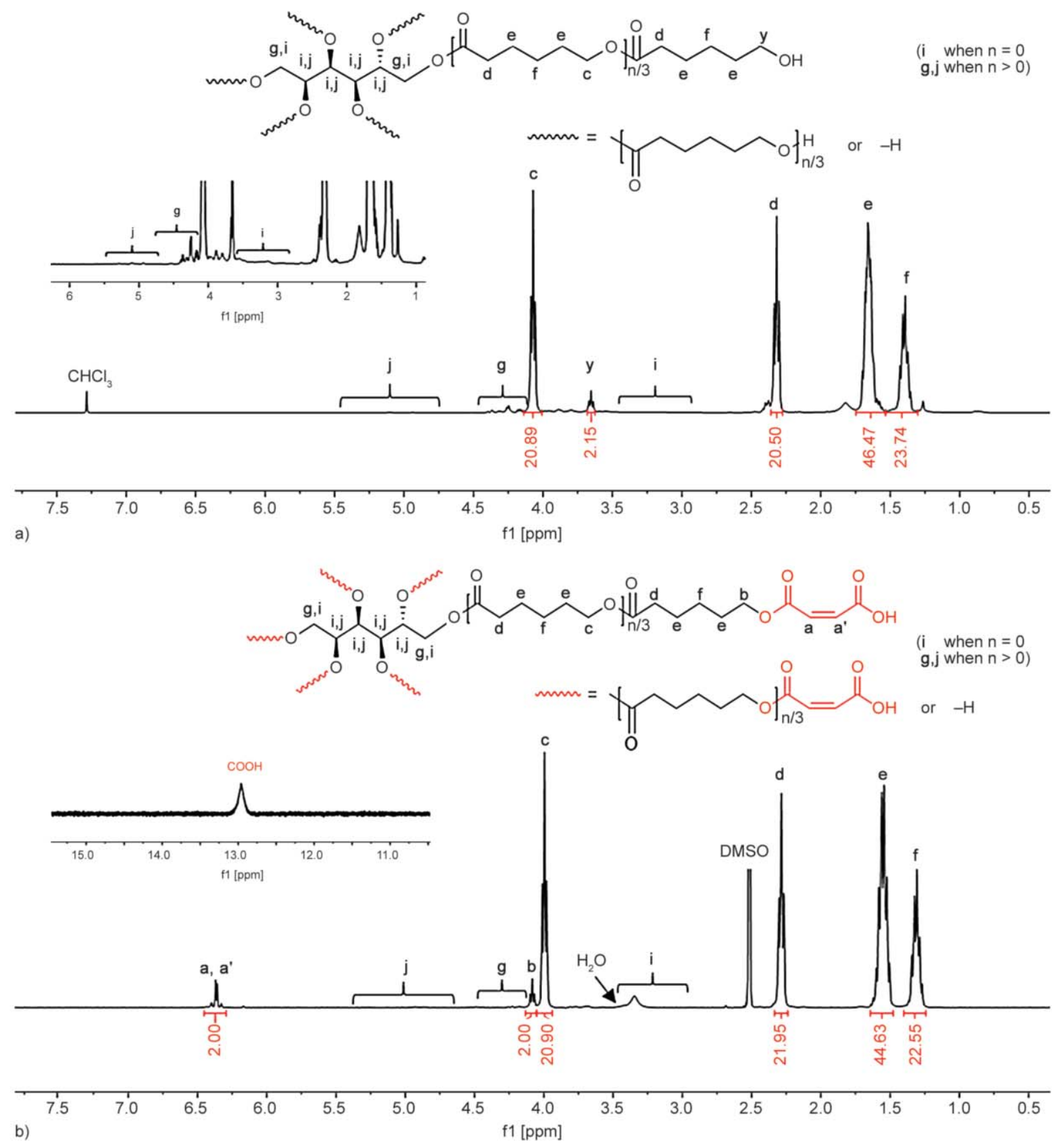

Figure 3. ${ }^{1} \mathrm{H}-\mathrm{NMR}$ spectra $(400 \mathrm{MHz})$ of purified (a) precursor star $D$-sorbitol[(PCL) $\left.{ }_{30} \mathrm{OH}_{3}\right] \mathrm{OH}_{3}$ in $\mathrm{CDCl}_{3}$ and (b) a PCL hemiester of maleic acid functionalized star $D$-sorbitol[(PCL) $\left.{ }_{30} \mathrm{COOH}_{3}\right] \mathrm{OH}_{3}$ in $\mathrm{DMSO}-d_{6}$. Inset in the (b) shows the signal corresponding to terminal $\mathrm{COOH}$.

alkene $\left(-\mathrm{CH}_{2}-\mathrm{O}-(\mathrm{C}=\mathrm{O})-\mathrm{CH}=\mathrm{CH}-, \mathbf{a}, \mathbf{a}^{\prime}\right)$. These confirm that the derivatization of star $D$-sorbitol[(PCL)nOHx] into star $D$-sorbitol-PCL-hemiester of maleic acid ( $D$-sorbitol[ $\left.\left.\mathrm{PCL}_{\mathrm{n}}-\mathrm{MA}_{\mathrm{x}}\right]\right)$ was successful.

It is noteworthy that the signals corresponding to protons $\mathbf{g}$ of the esterified primary carbon atoms appear between $\delta=4.0-4.4 \mathrm{ppm}$ and in the range of $\delta=5.0-5.5 \mathrm{ppm}$ for the protons $\mathbf{j}$ of the esterified secondary carbon atoms. The resonances of any pendant protons on the sorbitol core next to residual hydroxyl groups are expected to shift around $4 \mathrm{ppm}$ and overlap with resonances from the polymer backbone. However, due to a poor signal to noise ratio for the resonances of the protons of sorbitol which are located at the core of the structure, quantification based on the sorbitol signals from ${ }^{1} \mathrm{H}-\mathrm{NMR}$ is not reliable (see insets Figure 3a). It is important to emphasize that according to our previous study [26], the number of arms $\left(N_{\mathrm{arms}} \sim 3\right)$ is an average value, so the position of arms on $D$-sorbitol could only be assigned arbitrarily (especially for the secondary 
hydroxyls). For clarity, a 6-arm star-structure has been represented for NMR but in average 3-arms have grown from the sorbitol core.

Additionally, the $D P^{\mathrm{NMR}}$ calculated from the ratio of methylene signals $\mathbf{c}$ in the PCL backbone to the protons in $\alpha$-position of the maleate group $\mathbf{b}$ was found to be $\sim 10$. This gives an average of $\sim 10$ PCL units per arm, similar to the value before functionalization, which suggests that only the terminal primary hydroxyl chain-ends of PCL-arms were derivatized into hemiester of maleic acid, implying that $\sim 3$ pendant secondary hydroxyl groups remained on the $D$ sorbitol core. If the 3 pendant secondary hydroxyl groups of the $D$-sorbitol core had been functionalized, an increase in the ratio of methine protons (a, $\left.\mathbf{a}^{\prime}\right)$ over methylene function $\mathbf{b}$ would have been observed. This is not the case, as identified by ${ }^{1} \mathrm{H}-\mathrm{NMR}$ analysis (Figure $3 \mathrm{~b}$ ). Thus, it suggests that a star $D$ sorbitol $\left[(\mathrm{PCL})_{30} \mathrm{COOH}_{3}\right] \mathrm{OH}_{3}$ with an average of $\sim 3$ PCL hemiester of maleic acid functionalities and $\sim 3$ (secondary) pendant $\mathrm{OH}$ groups was synthesized under the conditions employed $\left(80^{\circ} \mathrm{C}, \sim 2 \mathrm{~h}\right.$, the absence of catalyst). In future work, it might be possible to quantify the carboxylic acid and hydroxyl functions by additional characterization techniques such as ${ }^{31} \mathrm{P}-\mathrm{NMR}$ after phosphitylation [26]. Since an excess of maleic anhydride was used (feed ratio of the star: $\mathrm{MAH}=1: 20$ ratios, thus $(20 \mathrm{MAH}) /(1-$ star $\times$ 6 hydroxyl groups) $=3$-fold excess of MAH), so as we expected, the ${ }^{1} \mathrm{H}-\mathrm{NMR}$ analyses of crude samples detected unreacted MAH. However, the purified sample showed the absence of MAH signals (Figure 3b). These data demonstrate that the hemiester of maleic acid is indeed covalently linked to PCL arms and a quantitative functionalization of PCL-OH arms into PCL-hemiester of maleic acid has occurred. The non-reactivity of the three remaining secondary hydroxyl groups of the sorbitol core with the three-fold excess of MAH is rather surprising and might be due to steric hindrance at the star core.

The electron acceptor/donor (A/D) molar ratio is an important parameter to consider when monitoring the photo-induced polymerization or crosslinking [35]. Among the choice of the electron donor, we selected tri(ethylene glycol) divinyl ether (DVE-3) because of its polar nature to favour its miscibility with the functionalized star PCL. Indeed, a quick test of dissolution $10 \mathrm{wt} \%$ ratio of S-PCL-MA3100 in DVE3 as a solvent has proven its excellent compatibility with it. Nonetheless, the formulation of a starting trifunctional star $D$-sorbitol-[PCL-MA] and bifunctional DVE-3 should have a stoichiometric proportion of A/D (i.e. 2:3 trifunctional A/difunctional D molar ratio) [35]. When choosing this proportion, the content of solid S-PCL-MA3100 in the A/D formulation is $\sim 91 \mathrm{wt} \%$. Hence, a good common solvent (acetone) at an optimized concentration ( $\sim 50 \mathrm{wt} \%$ respect to total feed) was necessary to obtain a homogeneous solution of the functionalized PCL star and DVE-3. It gave a clear and transparent mixture. After which the photoinitiator (Darocur 1173, $4 \mathrm{wt} \%$ respect to the total weight of the blend) was added. This formulation was employed to study the kinetics of polymerization by Real Time-FTIR and for UV-curing.

\subsection{Photopolymerization and kinetic analysis of star $D$-sorbitol [PCL-MA ${ }_{x}$ ] with DVE-3}

First, the acetone-borne films were cured by the fusion lamp with 20 passes under air. Then, the efficiency of UV-curing was determined using FTIR spectroscopy by comparing the intensity of the vinyl ether band of DVE-3 at 1615 and $1635 \mathrm{~cm}^{-1}$ to that of the carbonyl peak at $1726 \mathrm{~cm}^{-1}$ (Figure 4, top black line). Indeed, after UV curing under air (Figure 4 , red line), these two bands almost completely disappeared meaning quantitative conversion of the vinyl ether bonds.

To characterize the kinetics of the photocopolymerization, the light-induced polymerization between the maleate group and DVE-3 was then recorded by Real Time-FTIR spectroscopy, under UV-irradiation at the intensity of $10 \mathrm{~mW} \cdot \mathrm{cm}^{-2}$ under air (Figure 5a) and without air by protecting with a PP film (Figure $5 b$ ).

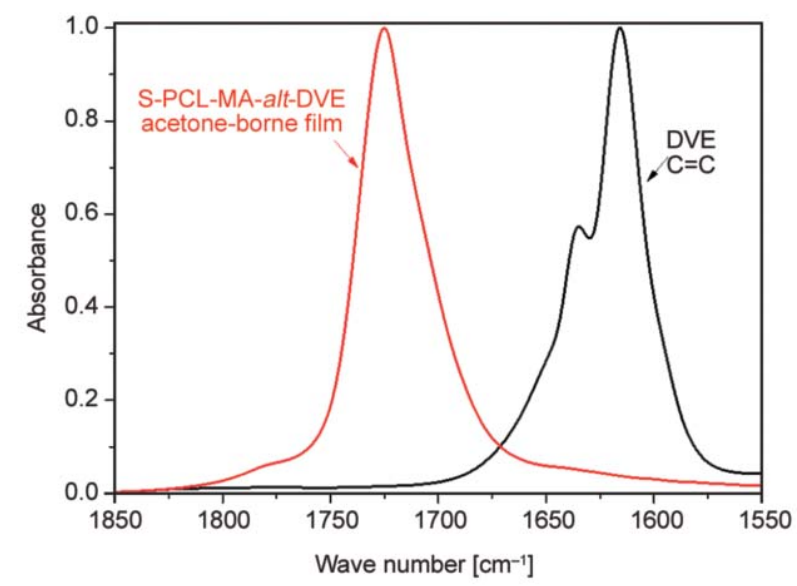

Figure 4. FTIR spectra of the DVE-3 monomer (black line) and the star $D$-sorbitol[ $\mathrm{PCL}_{\mathrm{n}}-\mathrm{MA}_{\mathrm{x}}$-alt-DVE $]$ acetone-borne UV-cured film (red line). 

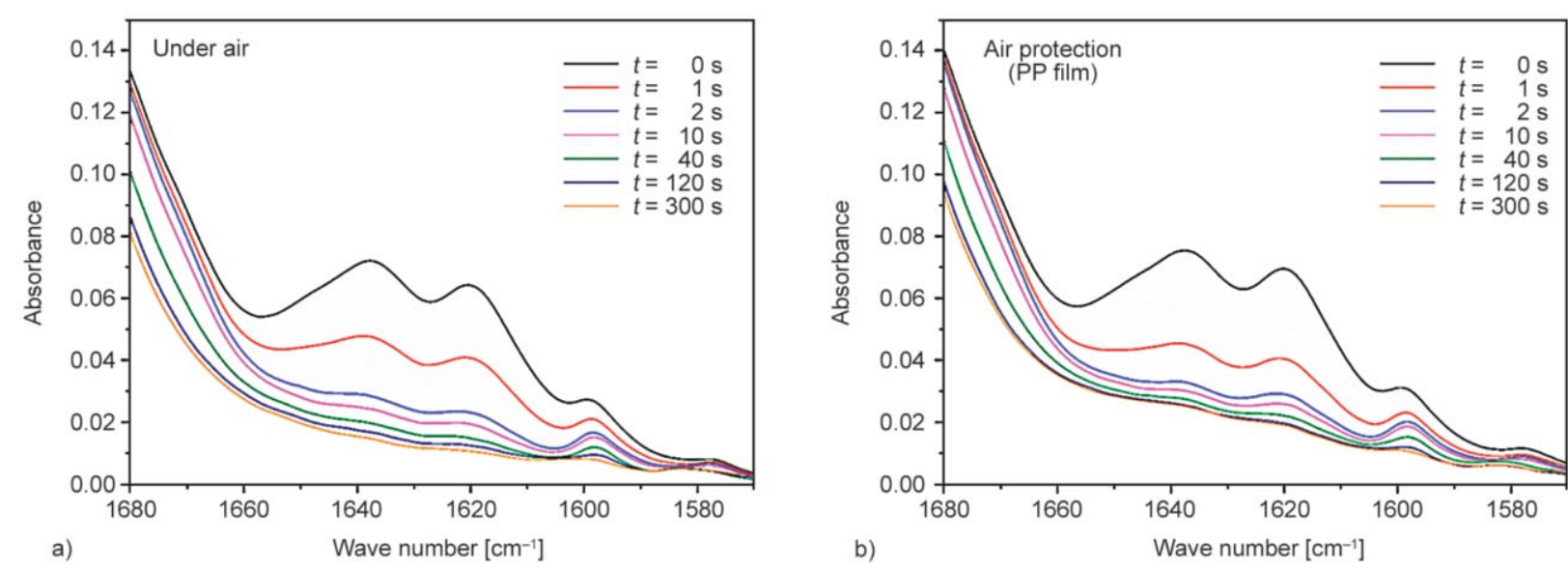

Figure 5. FTIR spectra showing the kinetics of the UV-polymerization of star $D$-sorbitol[PCL-MA $\mathrm{A}_{\mathrm{x}}$ with tri(ethylene glycol) divinyl ether over a reaction time of $300 \mathrm{~s}$ (the spectra are normalized using the carbonyl peak at $1726 \mathrm{~cm}^{-1}$ ). a) under air and b) without air by protecting with a PP film.

The conversion was continuously monitored in situ for $300 \mathrm{~s}$ following the decay of the IR bands at 1615 and $1635 \mathrm{~cm}^{-1}$ characteristic of the vinyl ether double bond correlated with Figure 4. The vinyl ether consumption was very fast whether the polymerization was performed in the absence of air or in contact with air. The reaction seems to be slightly faster in absence of air upon irradiation for $2 \mathrm{~s}$ (blue line, Figure $5 b)$.

A significant change is however not evidenced in the kinetic profiles (Figure 5) suggesting that the system is not sensitive to oxygen inhibition, which is an advantage over acrylate systems. Full vinyl ether conversion may be estimated from such profiles because the full decay of unsaturated groups is noticeable (Figure 5). Yet, the quantitative conversion of maleate could not be evaluated by FTIR due to overlapping between $\mathrm{C}=\mathrm{C}$ stretch band peaks of maleate and DVE-3. Additionally, it is also evident from

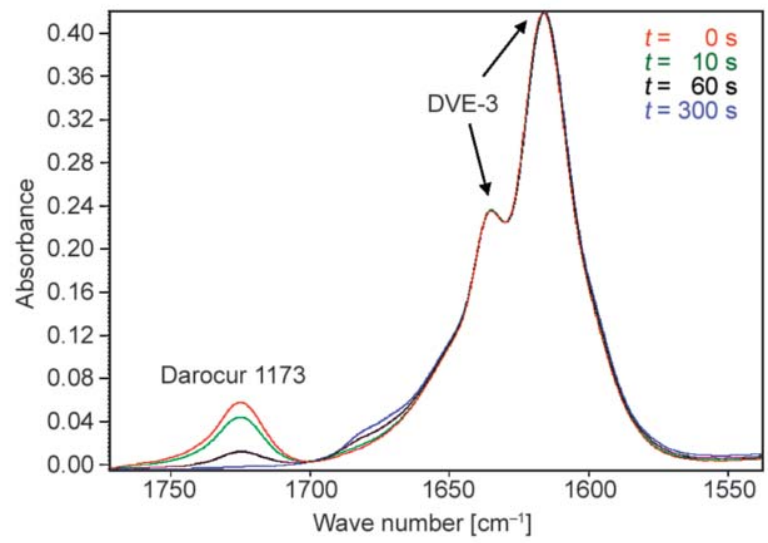

Figure 6. FTIR spectra for the UV-photopolymerization reaction of a mixture of DVE-3 monomer and Darocur 1173 at $4 \mathrm{wt} \%$.
FTIR spectra that the UV-light-induced photopolymerization of the starting DVE-3 in the presence of Darocur 1173 (at $4 \mathrm{wt} \%$ respect to DVE-3; i.e. the same ratio as that used for film formulations) into PDVE does not occur (Figure 6 and 7a). Vinyl ether compounds are known to photopolymerize with a cationic photoinitiator and not with a radical photoinitiator $[36,37]$.

Nevertheless, knowing that the vinyl ether cannot homopolymerize (Figure 7a), and given the stoichiometric ratio maleate/vinyl ether used in the experiment,
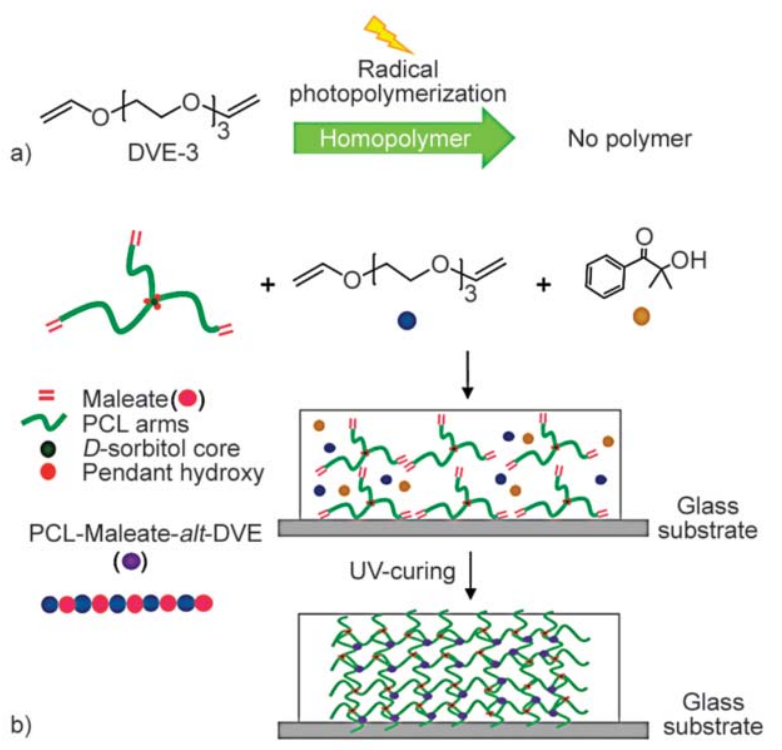

Figure 7. Representation of (a) the UV-induced DVE polymerization reaction and (b) schematic showing UV-induced $\quad D$-sorbitol[ $\mathrm{PCL}_{\mathrm{n}}-\mathrm{MA}_{\mathrm{x}}$-alt-DVE $\left.\mathrm{DV}_{\mathrm{y}}\right]$ coating; where maleate of star $D$-sorbitol- $\mathrm{PCL}_{\mathrm{n}}$ $\mathrm{MA}_{\mathrm{x}}$ (electron acceptor) (3 maleates per star polymer) with DVE-3 (electron donor) in the presence of Darocur 1173 as a photoinitiator are also represented. 
the full conversion of vinyl ether implies a full conversion of the maleate (Figure $7 b$ ).

\subsection{DSC analysis}

DSC thermograms show that the precursor S-PCL3100 and the functionalized S-PCL-MA3100 are both semi-crystalline (black and red in exotherm, Figure 8 ). The substitution of the terminal primary hydroxyl groups on the star PCL with hemiester of maleic acid only slightly increased the crystallization temperature (from $T_{\mathrm{c}}=27.2^{\circ} \mathrm{C}$ to $T_{\mathrm{c}}=29.8^{\circ} \mathrm{C}$ ) and the melting temperature (from $T_{\mathrm{m}}=34.3^{\circ} \mathrm{C}$ to $T_{\mathrm{m}}=$ $37.6^{\circ} \mathrm{C}$ ). Both S-PCL3100 and PCL-MA3100 exhibited two melting endotherms. The double melting behavior is more pronounced after end-group functionalization. Such multiple melting endotherms are rather a common phenomenon with branched polymers but often explained ambiguously [38-40]. Analysis of the S-PCL-MA-alt-DVE film revealed the amorphous nature of the network in both heating and cooling runs as the crosslinking process completely suppresses the crystallization. Indeed, the crosslinking density of the network suppressed the mobility of molecular chain, hence remarkably restricting the PCL crystal formation after the photocrosslinking reaction.

Such an effect has been observed previously, for example, in the case of the PCL crosslinking with poly (urethanes) [41], PCL fumarate [42] and PCL acrylate [43]. The glass transition temperature $\left(T_{\mathrm{g}}=-51.3^{\circ} \mathrm{C}\right)$ was identified after photocrosslinking reaction

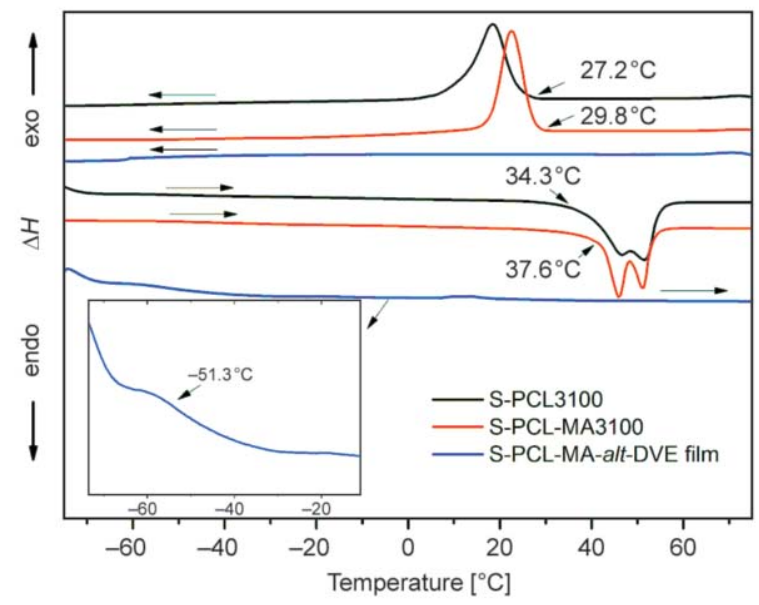

Figure 8. DSC curves of S-PCL3100 prepolymer (black line), hemiester of maleic acid functionalized S-PCLMA3100 (red line) and the S-PCL-MA-alt-DVE crosslinked networks (blue line). The inset shows the enlarged endotherm network for clarity of $T_{\mathrm{g}}$ in the case of the crosslinked film. because of the motion restriction imposed by the crosslinks. The observation of a single transition temperature $\left(T_{\mathrm{g}}\right)$ for the S-PCL-MA-alt-DVE film is good evidence that the sample is homogeneous. More information could be obtained by transmission electron microscopy to detect any phase separation.

\subsection{TGA analysis}

TGA has been performed to determine the thermal stability of both S-PCL3100, uncrosslinked S-PCLMA3100 and crosslinked S-PCL-MA-alt-DVE under an air environment. All samples show one single degradation step (Figure 9). The onset thermal degradation temperature $\left(T_{\mathrm{d}}\right)$ decreases slightly after crosslinking. $T_{\mathrm{d}, 10 \%}$ for S-PCL3100, S-PCL-MA3100 and crosslinked S-PCL-MA-alt-DVE in this study are 286,296 and $288^{\circ} \mathrm{C}$, respectively, corresponding to the total weight of the sample. The triethylene glycol of DVE-3 is thought to be prone to thermal degradation below $350^{\circ} \mathrm{C}$ under air (like oligo-ethylene glycol). Yet, despite the presence of about $9 \mathrm{wt} \%$ DVE-3 in its composition, the crosslinked S-PCLMA-alt-DVE polymer film retained thermal stability as good as its parent S-PCL-MA3100 functionalized star polymer. No significant change was observed in the decomposition profile of the starting S-PCL3100 and the crosslinked film. The final decomposition temperature corresponding to $90 \mathrm{wt} \%$ weight loss $\left(T_{\mathrm{d}, 90 \%}\right)$ for S-PCL-MA-alt-DVE was $443^{\circ} \mathrm{C}$, which is very close to parent S-PCL3100 at $433^{\circ} \mathrm{C}$ and its functionalized S-PCL-MA3100 at $437^{\circ} \mathrm{C}$.

\subsection{Gel content analysis}

To measure the gel content of the films, acetone was the solvent of choice. Indeed, it was a good solvent

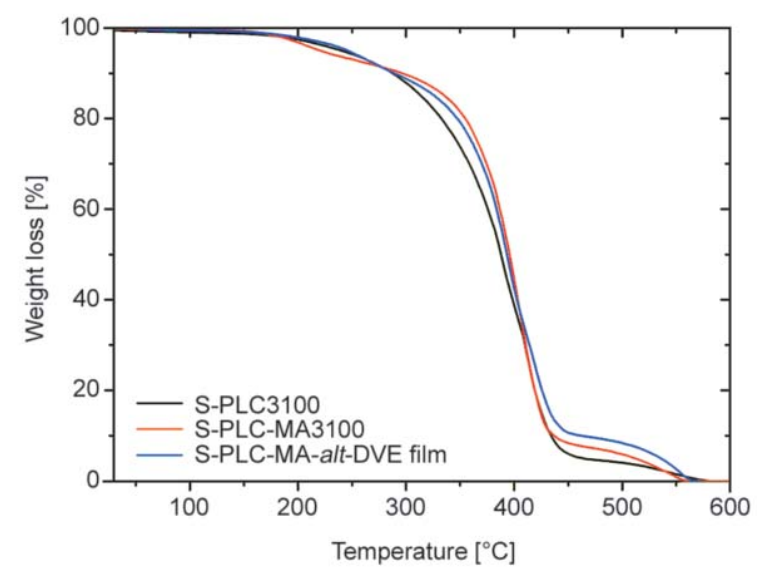

Figure 9. TGA thermograms under an air of S-PCL3100, SPCL-MA3100 and crosslinked S-PCL-MA-altDVE resin. 
allowing the solubility of the different monomers and their mixture. The coatings exhibited gel content values of $72 \%$ revealing that obvious crosslinking occurred. However, some chains seemed to be still partially soluble even if the IR and DSC analyses highlighted the consumption of both monomers: vinyl ether and maleate.

\subsection{Adhesion study}

An important factor in making a high-performance coating is to ensure excellent adhesion onto the various types of support. In this work, the pull-off adhesion test was performed to determine the adhesion of the S-PCL-MA-alt-DVE coating on glass, aluminum and steel substrates. On all of the substrates tried, the coating provided excellent adhesion. Indeed, they are all ranked at 5 based on the ASTM D3359 standard test with none of the squares of the lattice detached (Figure 10). Good adhesion of the coating may be attributed to the presence of polar hydroxyl groups that can form hydrogen bonding with substrates and in between the resin molecules and thereby boost the adhesion strength of the coatings.

\section{Conclusions}

A bio-based sorbitol-based polyester has been successfully employed for the preparation of solventborne resin. The UV-cured films of the functionalized S-PCL-MA star polymer $\left(3100 \mathrm{~g} \cdot \mathrm{mol}^{-1}\right)$ bearing three-hemiesters of maleic acid were successfully prepared by using a small amount of DVE-3 as comonomer and in the presence of Darocur 1173 as a radical photoinitiator. This amount of DVE-3 is only $\sim 10 \mathrm{wt} \%$ relative to the star polymer, corresponding to 3:2 molar ratio of star polymer to DVE-3 (i.e. a stoichiometric ratio of maleate electron acceptor to vinyl ether electron donor). During the UV irradiation, a quantitative conversion of the maleate and vinyl ether functions was demonstrated. The UV-curing was not very sensitive to inhibition by oxygen, in contrast to systems based on acrylates. Finally, the thermal properties of the crosslinked films have been studied. After crosslinking, the S-PCL maleate/ethylene glycol vinyl ether network completely loses the crystallinity and the films were amorphous. The thermal stability of the crosslinked S-PCL-MA-altDVE-3 polymer film was as good as its parent S-PCLMA3100 functionalized star polymer. In addition, the crosslinked films showed good adhesion on a glass, metallic and aluminum substrate. Future aspects of this study include the determination of the surface properties of these films by contact angle measurements. Furthermore, it would be interesting to study the behavior of the films in wet environment, for potential applications as coatings in food packaging or for anti-corrosion. Other divinyl ethers perhaps be introduced to provide higher hydrophobicity. And the number of functionalized arms as well as the PCL chain length could also be tuned to increase the crosslinking density and thus increase the gel content to minimize possible migration of small species.

\section{Acknowledgements}

The authors would like to acknowledge SINCHEM Joint Doctorate Program-Erasmus Mundus Action (framework agreement no. 2013-0037) as well as the European Union's Horizon 2020 Marie Skłodowska-Curie Actions program under Grant Agreement No. 690917 - PhotoFluo for funding.

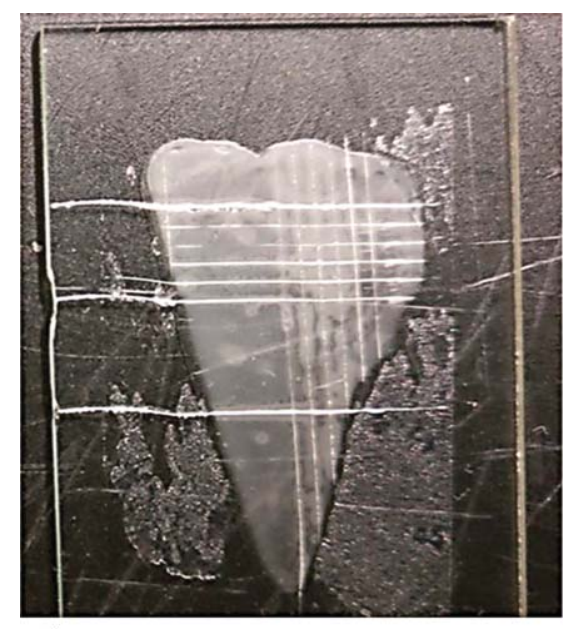

a)

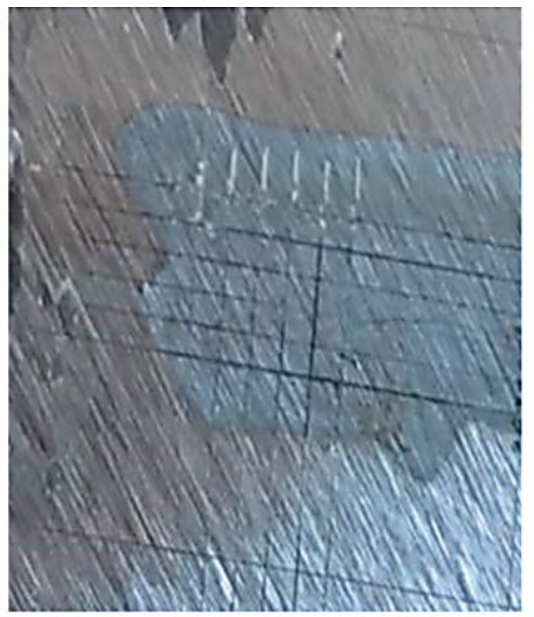

b)

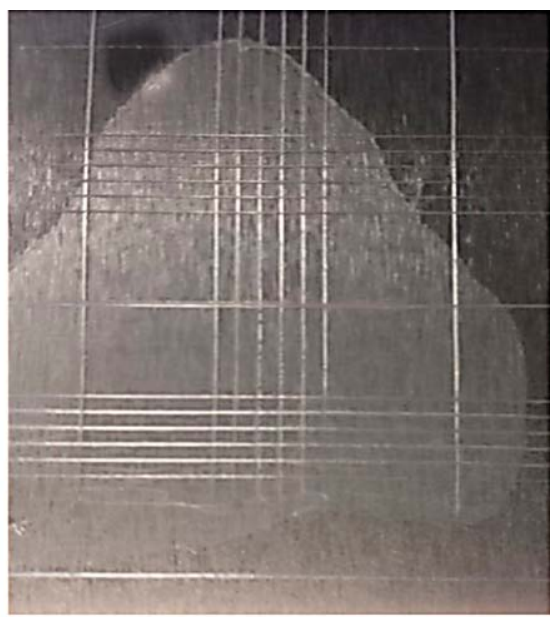

c)

Figure 10. Representing the strong adhesion of coated S-PCL-MA-alt-DVE resin on (a) glass, (b) steel and (c) aluminum substrates. 


\section{References}

[1] Gao C., Yan D.: Hyperbranched polymers: From synthesis to applications. Progress in Polymer Science, 29, 183-275 (2004).

https://doi.org/10.1016/j.progpolymsci.2003.12.002

[2] Claesson H., Malmström E., Johansson M., Hult A., Doyle M., Månson J-A. E.: Rheological behaviour during UV-curing of a star-branched polyester. Progress in Organic Coatings, 44, 63-67 (2002).

https://doi.org/10.1016/S0300-9440(01)00242-9

[3] van Benthem R. A. T.: Novel hyperbranched resins for coating applications. Progress in Organic Coatings, 40, 203-214 (2000).

https://doi.org/10.1016/S0300-9440(00)00122-3

[4] Chen Y., Wang N., Tong G., Wu D., Jin X., Zhu X.: Synthesis of multiarm star polymer based on hyperbranched polyester core and poly( $\varepsilon$-caprolactone) arms and its application in UV-curable coating. ACS Omega, 3, 13928-13934 (2018).

https://doi.org/10.1021/acsomega.8b02128

[5] Claesson H., Malmström E., Johansson M., Hult A.: Synthesis and characterisation of star branched polyesters with dendritic cores and the effect of structural variations on zero shear rate viscosity. Polymer, 43, 3511-3518 (2002).

https://doi.org/10.1016/S0032-3861(02)00073-3

[6] Irfan M., Oh J., Musharraf S. G., Shah M. R., Ahmed S., Malik M. I.: Synthesis and meticulous molecular, morphological and thermal characterization of linear and star-shaped polycaprolactones. RSC Advances, 6, 98117-98127 (2016).

https://doi.org/10.1039/C6RA23890D

[7] Sobczak M., Witkowska E., Olędzka E., Kolodziejski W.: Synthesis and structural analysis of polyester prodrugs of norfloxacin. Molecules, 13, 96-106 (2008). https://doi.org/10.3390/molecules13010096

[8] Dong C-M., Qiu K-Y., Gu Z-W., Feng X-D.: Synthesis of star-shaped poly( $\varepsilon$-caprolactone)-b-poly(DL-lactic acid-alt-glycolic acid) with multifunctional initiator and stannous octoate catalyst. Macromolecules, 34, 46914696 (2001).

https://doi.org/10.1021/ma010005w

[9] Sanda F., Sanada H., Shibasaki Y., Endo T.: Star polymer synthesis from $\varepsilon$-caprolactone utilizing polyol/protonic acid initiator. Macromolecules, 35, 680-683 (2002).

https://doi.org/10.1021/ma011341f

[10] Huang S., Xiao J., Zhu Y., Qu J.: Synthesis and properties of spray-applied high solid content two component polyurethane coatings based on polycaprolactone polyols. Progress in Organic Coatings, 106, 60-68 (2017). https://doi.org/10.1016/j.porgcoat.2017.02.011
[11] Deokar M. D., Idage S. B., Idage B. B., Sivaram S.: Synthesis and characterization of well-defined random and block copolymers of $\varepsilon$-caprolactone with L-lactide as an additive for toughening polylactide: Influence of the molecular architecture. Journal of Applied Polymer Science, 133, 43267/1-43267/12 (2016).

https://doi.org/10.1002/app.43267

[12] Johansson M., Malmström E., Jansson A., Hult A.: Novel concept for low temperature curing powder coatings based on hyperbranched polyesters. Journal of Coatings Technology, 72, 49-54 (2000).

https://doi.org/10.1007/BF02698470

[13] Lange J., Stenroos E., Johansson M., Malmström E.: Barrier coatings for flexible packaging based on hyperbranched resins. Polymer, 42, 7403-7410 (2001).

https://doi.org/10.1016/S0032-3861(01)00189-6

[14] Torron S., Hult D., Pettersson T., Johansson M.: Tailoring soft polymer networks based on sugars and fatty acids toward pressure sensitive adhesive applications. ACS Sustainable Chemistry and Engineering, 5, 26322638 (2017).

https://doi.org/10.1021/acssuschemeng.6b02978

[15] Gustini L., Noordover B. A. J., Gehrels C., Dietz C., Koning C. E.: Enzymatic synthesis and preliminary evaluation as coating of sorbitol-based, hydroxy-functional polyesters with controlled molecular weights. European Polymer Journal, 67, 459-475 (2015).

https://doi.org/10.1016/j.eurpolymj.2014.12.025

[16] Marques C., Tarek R., Sara M., Brar S. K.: Sorbitol production from biomass and its global market. in 'Platform Chemical Biorefinery' (eds.: Brar S. K., Sarma S. J., Pakshirajan K.) Elsevier, Amsterdam, 217-227 (2016). https://doi.org/10.1016/B978-0-12-802980-0.00012-2

[17] Isikgor F. H., Becer C. R.: Lignocellulosic biomass: A sustainable platform for the production of bio-based chemicals and polymers. Polymer Chemistry, 6, 44974559 (2015).

https://doi.org/10.1039/C5PY00263J

[18] Okkerse C., van Bekkum H.: From fossil to green. Green Chemistry, 1, 107-114 (1999).

https://doi.org/10.1039/a809539f

[19] Corma A., Iborra S., Velty A.: Chemical routes for the transformation of biomass into chemicals. Chemical Reviews, 107, 2411-2502 (2007).

https://doi.org/10.1021/cr050989d

[20] Sun Y., Cheng J.: Hydrolysis of lignocellulosic materials for ethanol production: A review. Bioresource Technology, 83, 1-11 (2002). https://doi.org/10.1016/S0960-8524(01)00212-7

[21] Haq F., Ali H., Shuaib M., Badshah M., Hassan S. W., Munis M. F. H., Chaudhary H. J.: Recent progress in bioethanol production from lignocellulosic materials: A review. International Journal of Green Energy, 13, 1413-1441 (2016). https://doi.org/10.1080/15435075.2015.1088855 
[22] Kobayashi H., Fukuoka A.: Synthesis and utilisation of sugar compounds derived from lignocellulosic biomass. Green Chemistry, 15, 1740-1763 (2013).

https://doi.org/10.1039/c3gc00060e

[23] Palmans A. R. A., Heise A.: Enzymatic polymerisation. Springer, Berlin (2010).

[24] Zhang J., Shi H., Wu D., Xing Z., Zhang A., Yang Y., Li Q.: Recent developments in lipase-catalyzed synthesis of polymeric materials. Process Biochemistry, 49, 797-806 (2014).

https://doi.org/10.1016/j.procbio.2014.02.006

[25] Semlitsch S., Torron S., Johansson M., Martinelle M.: Enzymatic catalysis as a versatile tool for the synthesis of multifunctional, bio-based oligoester resins. Green Chemistry, 18, 1923-1929 (2016).

https://doi.org/10.1039/C5GC02597D

[26] Baheti P., Gimello O., Bouilhac C., Lacroix-Desmazes P., Howdle S. M.: Sustainable synthesis and precise characterisation of bio-based star polycaprolactone synthesised with a metal catalyst and with lipase. Polymer Chemistry, 9, 5594-5607 (2018).

https://doi.org/10.1039/C8PY01266K

[27] Lyon S. B., Bingham R., Mills D. J.: Advances in corrosion protection by organic coatings: What we know and what we would like to know. Progress in Organic Coatings, 102, 2-7 (2017).

https://doi.org/10.1016/j.porgcoat.2016.04.030

[28] Decker C.: UV-radiation curing of adhesives. in 'Handbook of adhesives and surface preparation' (ed.: Ebnesajjad S.) Elsevier, Amsterdam, 221-243 (2011).

https://doi.org/10.1016/B978-1-4377-4461-3.10010-0

[29] Hoyle C. E., Clark S. C., Jonsson S., Shimose M.: Photopolymerization using maleimides as photoinitiators. Polymer, 38, 5695-5697 (1997).

https://doi.org/10.1016/S0032-3861(97)00181-X

[30] Yagci Y., Jockusch S., Turro N. J.: Photoinitiated polymerization: Advances, challenges, and opportunities. Macromolecules, 43, 6245-6260 (2010). https://doi.org/10.1021/ma1007545

[31] Ligon S. C., Husár B., Wutzel H., Holman R., Liska R.: Strategies to reduce oxygen inhibition in photoinduced polymerization. Chemical Reviews, 114, 577-589 (2014). https://doi.org/10.1021/cr3005197

[32] Haraldsson T., Johansson M., Hult A.: The effects of abstractable hydrogen in radical photopolymerization of maleate/vinyl ether monomers studied with EPR and photo-RTIR. Journal of Polymer Science Part A: Polymer Chemistry, 48, 2810-2816 (2010).

https://doi.org/10.1002/pola.24050

[33] Decker C., Decker D.: Photoinitiated radical polymerization of vinyl ether-maleate systems. Polymer, 38, 2229-2237 (1997).

https://doi.org/10.1016/S0032-3861(96)00758-6
[34] Lacroix-Desmazes P., Guyot A.: Reactive surfactants in heterophase polymerization. 2. Maleate based poly(ethylene oxide) macromonomers as steric stabilizer precursors in the dispersion polymerization of styrene in ethanol-water media. Macromolecules, 29, 4508-4515 (1996).

https://doi.org/10.1021/ma951849g

[35] Morel F., Decker C., Jönsson S., Clark S. C., Hoyle C. E.: Kinetic study of the photo-induced copolymerization of $N$-substituted maleimides with electron donor monomers. Polymer, 40, 2447-2454 (1999).

https://doi.org/10.1016/S0032-3861(98)00449-2

[36] Decker C., Bianchi C., Decker D., Morel F.: Photoinitiated polymerization of vinyl ether-based systems. Progress in Organic Coatings, 42, 253-256 (2001). https://doi.org/10.1016/S0300-9440(01)00203-X

[37] Crivello J. V., Bratslavsky S. A.: Novel cationically polymerizable propenyl and vinyl ethers derived from renewable sources. Journal of Polymer Science: Part A Polymer Chemistry, 32, 2919-2930 (1994). https://doi.org/10.1002/pola.1994.080321513

[38] Li Y., Kissel T.: Synthesis, characteristics and in vitro degradation of star-block copolymers consisting of Llactide, glycolide and branched multi-arm poly(ethylene oxide). Polymer, 39, 4421-4427 (1998). https://doi.org/10.1016/S0032-3861(97)10362-7

[39] Tasaka F., Miyazaki H., Ohya Y., Ouchi T.: Synthesis of comb-type biodegradable polylactide through depsipeptide-lactide copolymer containing serine residues. Macromolecules, 32, 6386-6389 (1999).

https://doi.org/10.1021/ma990766n

[40] Turunen M. P. K., Korhonen H., Tuominen J., Seppälä J. V.: Synthesis, characterization and crosslinking of functional star-shaped poly( $\varepsilon$-caprolactone). Polymer International, 51, 92-100 (2002).

https://doi.org/10.1002/pi.805

[41] Mi H-Y., Jing X., Yilmaz G., Hagerty B. S., Enriquez E., Turng L-S.: In situ synthesis of polyurethane scaffolds with tunable properties by controlled crosslinking of tri-block copolymer and polycaprolactone triol for tissue regeneration. Chemical Engineering Journal, 348, 786-798 (2018). https://doi.org/10.1016/j.cej.2018.04.198

[42] Wang S., Yaszemski M. J., Gruetzmacher J. A., Lu L.: Photo-crosslinked poly( $\varepsilon$-caprolactone fumarate) networks: Roles of crystallinity and crosslinking density in determining mechanical properties. Polymer, 49, 5692-5699 (2008). https://doi.org/10.1016/j.polymer.2008.10.021

[43] Kweon H. Y., Yoo M. K., Park I. K., Kim T. H., Lee H. C., Lee H-S., Oh J-S., Akaike T., Cho C-S.: A novel degradable polycaprolactone networks for tissue engineering. Biomaterials, 24, 801-808 (2003). https://doi.org/10.1016/S0142-9612(02)00370-8 